Eur. J. Clin. Chem. Clin. Biochem.

Vol. 31, 1993, pp. 567-574

(C) 1993 Walter de Gruyter \& Co.

Bcrlin - New York

\title{
Soluble Interleukin-2 Receptor and Urinary Neopterin Concentrations in Malignant Lymphoma
}

\author{
By L. Piccinini ${ }^{1}$, Sandra Zironi ${ }^{2}$, Anna Maria Cenci ${ }^{3}$, D. Campioli ${ }^{3}$, M. Federico $^{2}$ and F. Barbieri ${ }^{2}$ \\ 1 Medical Therapy, University of Modena, Modena, Italy \\ 2 Medical Oncology, University of Modena, Modena, Italy \\ ${ }^{3}$ Department of Clinical Pathology, Policlinico Modena, Modena, Italy
}

(Received October 7, 1992/November 24, 1993)

Summary: The serum concentrations of soluble interleukin-2 receptors and urine neopterin were studied in 82 patients with malignant lymphomas (25 patients with Hodgkin's disease and 57 patients with non-Hodgkin's lymphoma.

Increases in soluble interleukin-2 receptors and in urinary neopterin were significantly correlated with the clinical phase of the disease. The average values in both Hodgkin's disease and non-Hodgkin's lymphoma patients suffering from the disease in its active phase were significantly higher than those of patients in complete remission. Neopterin concentrations (but not soluble interleukin-2 receptor concentrations) were also elevated in clinical stages III - IV of each disease. Urinary neopterin correlated directly and significantly with the erythrocyte sedimentation rate and inversely with haemoglobin. Finally, a longitudinal analysis showed a general tendency for the markers to return to normal values, in accordance with the favourable outcome of therapy; this was more evident for urinary neopterin than for soluble interleukin-2 receptors. These findings seem to confirm that soluble interleukin-2 receptors and especially urinary neopterin can be useful markers for monitoring and prognosis of malignant lymphomas.

\section{Introduction}

Interleukin-2 is a soluble lymphokine released by activated $\mathrm{T}$ helper lymphocytes, which promotes

a) the proliferation of $\mathrm{T}$ and $\mathrm{B}$ lymphocytes.

b) the cytotoxic activity of $\mathrm{T}$ lymphocytes and of natural killer cells and lymphokine activated killer cells, and

c) the secretion of immunoglobulin in B normal and neoplastic lymphocytes $(1-3)$.

Interleukin-2 is a glycoprotein that binds to specific receptors (interleukin-2 receptors) expressed on the cell membrane of the activated $\mathrm{T}$ and $\mathrm{B}$ lymphocytes and monocytes. An interleukin-2 receptor consists of two polypeptide chains ( $\alpha$ and $\beta$ ) which, when in close proximity to each other, constitute a high-affinity receptor. Both normal activated and neoplastic lymphocytes release a soluble receptor for interleukin-2 (soluble interleukin-2 receptors). These soluble receptors bind interleukin-2, and by competing with the receptors on the cell membrane, they may inhibit the interleukin-2-dependent immune responses (4-6).

Recently, abnormally increased concentrations of interleukin-2 receptors have been reported in various diseases, both tumoral (lymphomatosis $(7,8)$ and solid tumours $(9,10)$ and non-tumoral (autoimmune and viral conditions, collagenosis $(11-13))$, which feature different types of modification and/or activation of the immune system.

Neopterin, which was isolated from human urine more than a decade ago, is a pteridine compound deriving from guanosine triphosphate. Pteridines are 
molecules that are active in various biological events such as cell growth, regulation of immune responses and amine synthesis, and modulation of the endocrine system. Pteridine concentrations in cells and blood rise during periods of intense cell proliferation, as in the lymphocyte immune reaction and the replication of certain types of tumour cells. Pteridines play a specific role in the qualitative and quantitative mechanisms of interleukin-2-dependent lymphocyte responses in immune functions $(14,15)$. In tumours, particularly in cases of haematological malignancies, pteridines are metabolized to produce high concentrations of tetrahydrobiopterin in the blood, and of biopterin and neopterin in the urine $(16-18)$. Another point of major interest is that $\gamma$-interferon (produced by $\mathrm{T}$-lymphocytes following stimulation by tumour antigens and natural killer cells acitvated with interleukin-2) induces the secretion, by macrophages, of neopterin, which is then excreted in the urine. Preliminary studies report increased urinary neopterin in patients with lymphomas and carcinomas of the genital-urinary tract and the lungs $(19-21)$. Recently it was reported that soluble interleukin-2 receptors $(22,23)$ and urinary neopterin $(24-30)$ concentrations may be important markers not only in the monitoring but also in the prognosis of neoplastic diseases.

In the light of the foregoing, we studied serum soluble interleukin-2 receptor concentrations and urinary neopterin concentrations in patients with Hodgkin's disease and non-Hodgkin's lymphomas, which were unaffected by other pathologies (autoimmune diseases, collagenosis or viral infections) that might distort the findings.

\section{Materials and Methods}

Patients of both sexes between 20 and 80 years, 25 with Hodgkin's disease and 57 with non-Hodgkin's lymphomas were investigated. Soluble interleukin-2 receptors were determined in the blood and neopterin in the urine (tab. 1).

Correlations were also sought between the concentrations of soluble interleukin-2 receptors and urinary neopterin and the clinical phase of the disease (activity versus remission). Preliminary screening had shown that patients with complete or incomplete remission ( 8 and 12 cases, respectively) could be pooled, since their data overlapped; this also correlated with extremely low numbers of residual tumour cells and a resulting low immune response. Blood interleukin-2 receptors and urine neopterin were measured in patients during the active phase of the disease before treatment and in those during the remissive phase 3 weeks after the end of induction therapy, when remission had been confirmed. The concentrations of the two markers in patients with active Hodgkin's disease and non-Hodgkin's lymphoma were also correlated with the clinical stage (Stages I and II versus Stages III and IV of the Ann Arbor classification), with the general symptoms (presence $B$, absence $A$ ) and with the histological type (Rye Conference classification for Hodgkin's disease and the Working Formulation of non-Hodgkin's lymphoma $(31,32)$ ). In 8 cases, the 2 quantities were
Tab. 1. Patients' main characteristics

\begin{tabular}{lr}
\hline Total & 82 \\
Males & 45 \\
Females & 37 \\
Histological subtype & \\
Hodgkin's disease & 25 \\
LP/NS & 16 \\
MC/LD & 9 \\
Non-Hodgkin's lymphoma & 57 \\
Low grade & 21 \\
Intermediate/high grade & 36 \\
Disease phase & \\
Remission & \\
Hodkin's disease & 20 \\
Non-Hodgkin's lymphoma & 8 \\
Activity & 12 \\
Hodgkin's disease & 62 \\
Non-Hodgkin's lymphoma & 17 \\
\hline
\end{tabular}

Legend: LP, Lymphocyte predominance; NS, Nodular sclerosis; MC, Mixed cellularity; DL, Lymphocyte depletion.

assayed before and after the planned induction therapy with confirmed remission in a longitudinal study. Other quantities currently used in clinical monitoring (erythrocyte sedimentation rate, haemoglobin, white blood corpuscles, lymphocytes and monocytes, lactate dehydrogenase, $\alpha_{2}$-globulins, albumin) were also taken into account.

\section{Statistical analysis}

Data were stored in a computerized data base (db4, Ashton Tate) and processed using the SPSS statistical package (SPSS Inc.). Differences between the means of groups were tested for significance with the non-parametric Mann-Whitney (Wilcoxon) test. Relationships between soluble interleukin-2 receptors, urinary neopterin and other quantities were investigated by calculating Pearson product-moment correlations for pairs of variables.

\section{Assay method}

\section{Soluble interleukin-2 receptors}

Serum was frozen at $-20^{\circ} \mathrm{C}$, stored in small aliquots, then assayed by an enzyme-linked immunosorbent assay (ELISA), recently marketed for research purposes (Interleukin-2 Receptor Test Kit from T-Cell Sciences Inc., Cambridge (MA), distributed by Medical Systems S. P. A.). It uses a murine monoclonal antibody for interleukin-2 receptors adsorbed in polystyrene micro-traps to which the patient's serum is added; non-reactive elements are washed away. A second murine monoclonal antibody, specific for interleukin-2 receptors, and conjugated with horseradish peroxidase, is then added to bind a second epitope to the molecule captured by the first antibody. The interleukin2 receptor antibody conjugated with the free enzyme is removed by further washing and the substrate is added. The reaction is stopped and read at 490 nanometres. The mean absorption value of paired samples is calculated from a standard curve based on 4 points at different concentrations. Blood soluble interleukin-2 receptor values are expressed in units $(U)$ per litre. Samples requiring dilution are diluted in their own buffer. 
Reference standards were first obtained from 150 subjects with normal anamnesis and normal main metabolic functions, who were free from acute or chronic illness. The readings ranged from 116 to $402 \times 10^{3} \mathrm{U} / \mathrm{l}$, in exact agreement with the data reported in the literature.

\section{Urinary neopterin $(24,28)$}

Morning urine samples were collected and frozen at $-20^{\circ} \mathrm{C}$ until analysis. Since urinary neopterin concentrations are related to urinary creatinine, both were measured to account for physiological variations in urinary concentrations.

A Varian 5500 liquid chromatograph equipped with a Varian 8085 autosampler was used, with a reversed-phase C18 analytical column run at $0.8 \mathrm{ml} / \mathrm{min}$ flow rate under isocratic conditions. Separation was performed with Soerensen phosphate buffer (pH 6.4, $15 \mathrm{mmol} / \mathrm{l}$, flow $1 \mathrm{ml} / \mathrm{min}$ ).

Creatinine was monitored at $235 \mathrm{~nm}$ with a Varian UV 200 detector. A Varian 2070 spectrophotometer was set at $360 \mathrm{~nm}$ excitation wavelength and $420 \mathrm{~nm}$ emission wavelength, and neopterin was quantified from the peak area using a Vista 402 System and the external standard method. Results were expressed as the neopterin to creatinine ratio.

\section{Results}

Serum interleukin-2 receptors and urinary neopterin correlated closely with the active phase of the disease (fig. 1a-d). The 8 patients with Hodgkin's disease in remission and the 12 with non-Hodgkin's lymphoma in remission exhibited highly-significant decreases in the quantities in question, interleukin-2 receptors tending to approach the upper normal threshold limit $\left(771 \pm 450 \times 10^{3} \mathrm{U} / 1\right.$ and $610 \pm 586 \times 10^{3} \mathrm{U} / \mathrm{l}$, respectively), while neopterin was practically normal $(173 \pm 78 \mu \mathrm{mol} / \mathrm{mol}$ and $198 \pm 95 \mu \mathrm{mol} / \mathrm{mol}$, respectively). In the 17 patients with active Hodgkin's disease and the 45 patients with active non-Hodgkin's lymphoma, there were highly-significant increases in both interleukin-2 receptors $\left(2363 \pm 2876 \times 10^{3} \mathrm{U} / \mathrm{l}\right.$ : $\left.\mathrm{p}=0.003 ; 3634 \pm 5667 \times 10^{3} \mathrm{U} / \mathrm{l}: \mathrm{p}=0.0003\right)$ and neopterin $(394 \pm 295 \mu \mathrm{mol} / \mathrm{mol}: \mathrm{p}=0.002 ; 610$ $\pm 586 \mu \mathrm{mol} / \mathrm{mol}: \mathrm{p}<0.0001$ ); furthermore, in these cases, the interleukin-2 receptor values did not vary significantly with the clinical stage, whereas the neopterin values were significantly higher in stage III - IV than in stage I-II patients in both Hodgkin's disease and non-Hodgkin's lymphoma groups (525 \pm 317 $\mu \mathrm{mol} / \mathrm{mol}$ versus $227 \pm 97 \mu \mathrm{mol} / \mathrm{mol}, \mathrm{p}=0.018 ; 790$ $\pm 61 \mu \mathrm{mol} / \mathrm{mol}$ versus $422 \pm 194 \mu \mathrm{mol} / \mathrm{mol}$, $\mathrm{p}=0.0003$ ) (fig. $1 \mathrm{e}-\mathrm{h}$ ). In relation to the presence of B symptoms in non-Hodgkin's lymphoma patients, but not in Hodgkin's disease patients, significantly higher values were recorded only for urinary neopterin (B: $974 \pm 752 \mu \mathrm{mol} / \mathrm{mol}$ versus A: $555 \pm 360 \mu \mathrm{mol} /$ $\mathrm{mol}, \mathrm{p}=0.023$ ); also, only urinary neopterin correlated directly and significantly with the erythrocyte sedimentation rate $(p=0.003 R=0.31)$ and in- versely with haemoglobin ( $p=0.000 R=-0.40)$. There was a direct, though not statistically significant correlation between soluble interleukin-2 receptors and urinary neopterin.

In the Hodgkin's disease and non-Hodgkin's lymphoma groups, the histological subtype showed no significant correlation with the grades of malignancy. In the eight patients in the longitudinal study, there was a general tendency for the markers to approximate to normal values when the outcome of therapy was favourable; this was more evident for urinary neopterin than for interleukin-2 receptors (fig. 2).

\section{Discussion}

Our findings, and those reported in the available literature contain elements of considerable clinical and biological interest.

Increases in blood soluble interleukin-2 receptors have been observed both in patients with leukaemia (particularly T-cell lymphocytic leukaemia, hairy cell leukaemia and chronic B-cell lymphocytic leukaemia) and in those with lymphomas (non-Hodgkin's lymphoma, Hodgkin's disease), to the extent that blood soluble interleukin-2 receptors might well be thought to be of particular importance in the monitoring of these diseases $(23,33-36)$. Similar increases have been recorded in $70 \%$ of non-Hodgkin's lymphoma patients; they are generally reported as being linked to the extent of the disease and, as such, to serve as an indicator of tumour bulk (23), but this is apparently at variance with our findings. Our data indeed show an increase in soluble interleukin-2 receptor serum concentrations with advanced disease, but this is not statistically significant, probably due to the small number of patients and a wide dispersion of individual values. The values tend to normalize following complete clinical remission after therapy. In many cases, particularly in infancy, the increase in blood soluble interleukin-2 receptors has a negative prognostic value even greater than of other quantities (histological type, clinical stage, diagnosis of marrow involvement, lactate dehydrogenase) in predicting the length of the disease-free interval and overall survival period (35).

High blood soluble interleukin-2 receptors have also been found in $70 \%$ of Hodgkin's disease patients at the outset; the values are higher in advanced stages of the disease (stages III-IV, the presence of bulky disease) and in the presence of systemic symptomatology, in both adults and children. A good clinical response to therapy correlates with rapid normaliza- 

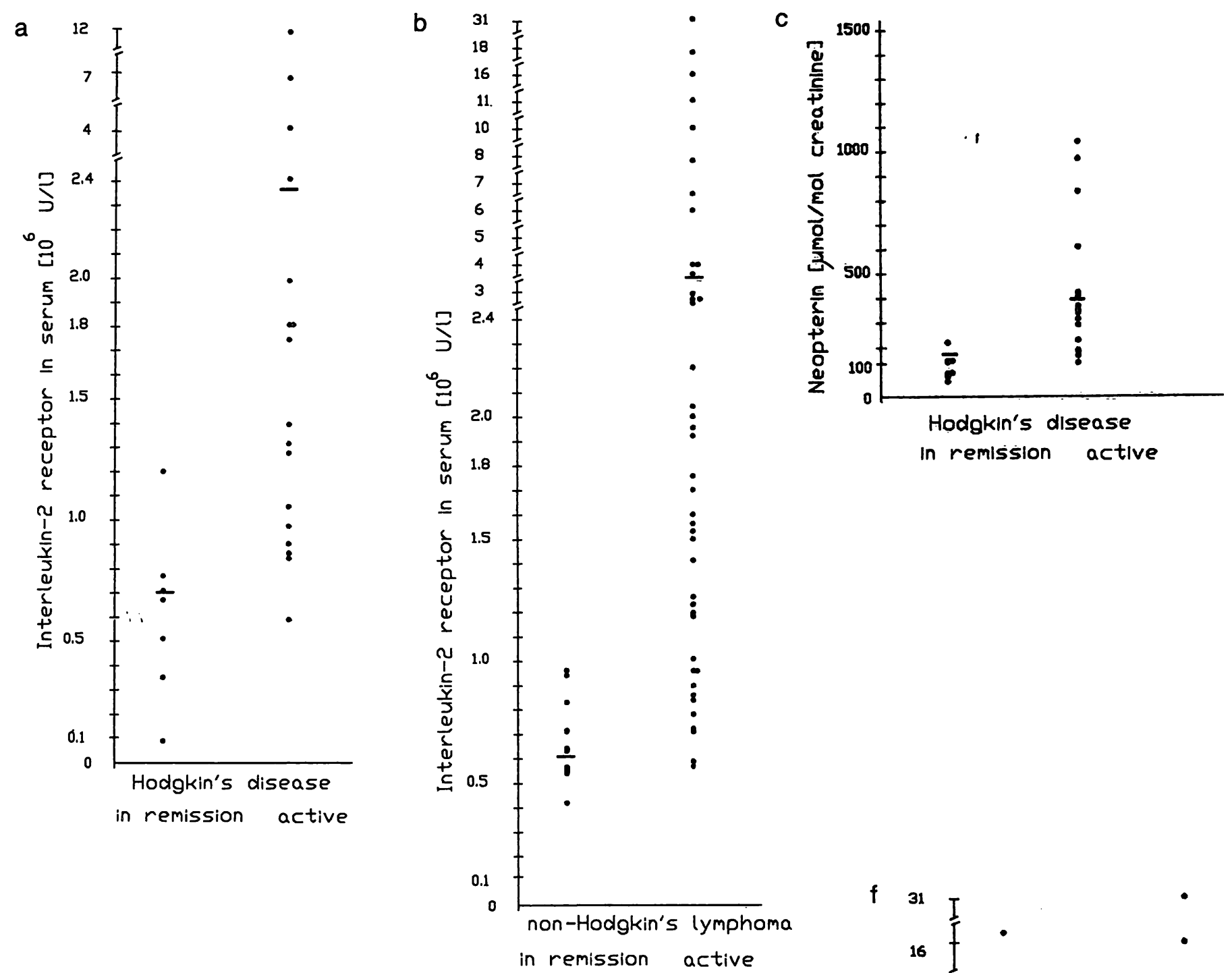

d

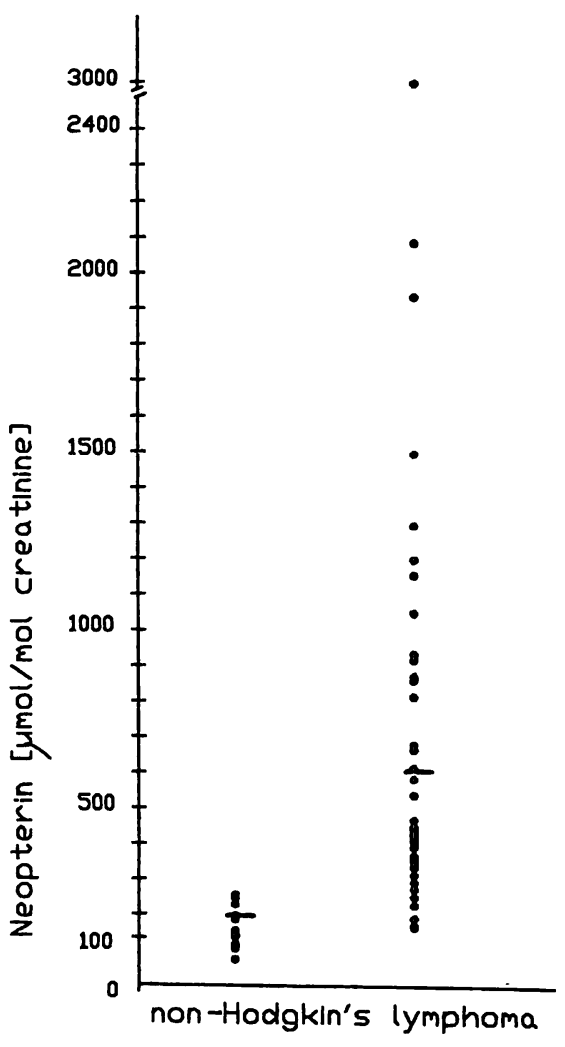

in remission active

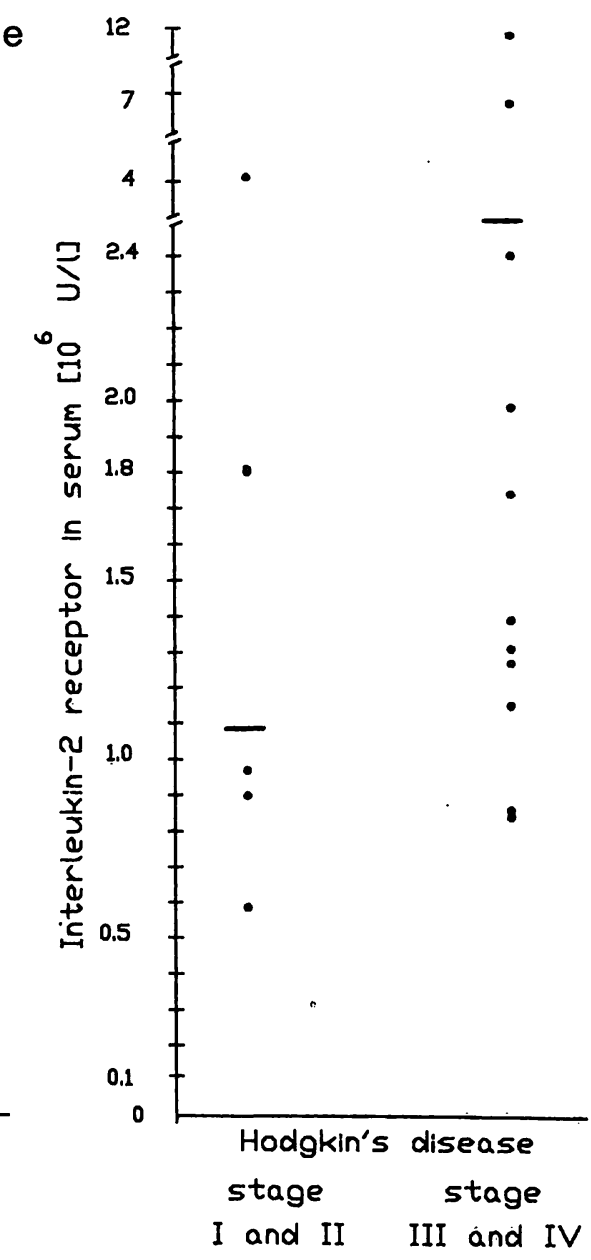

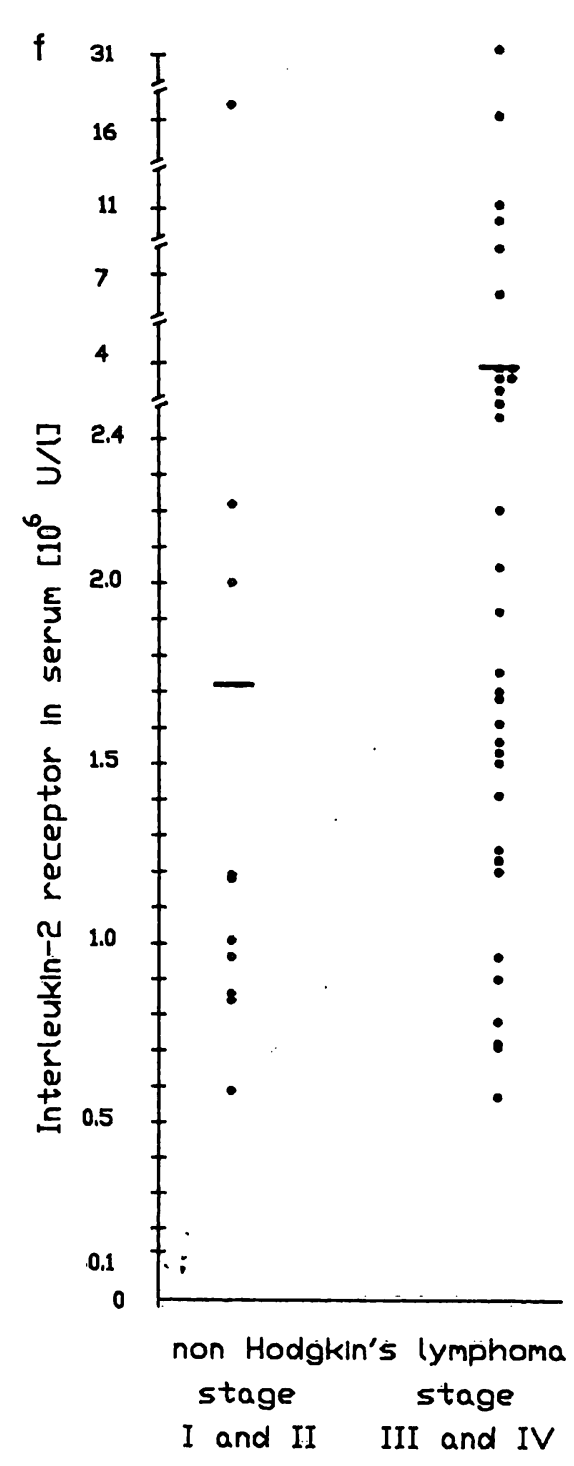



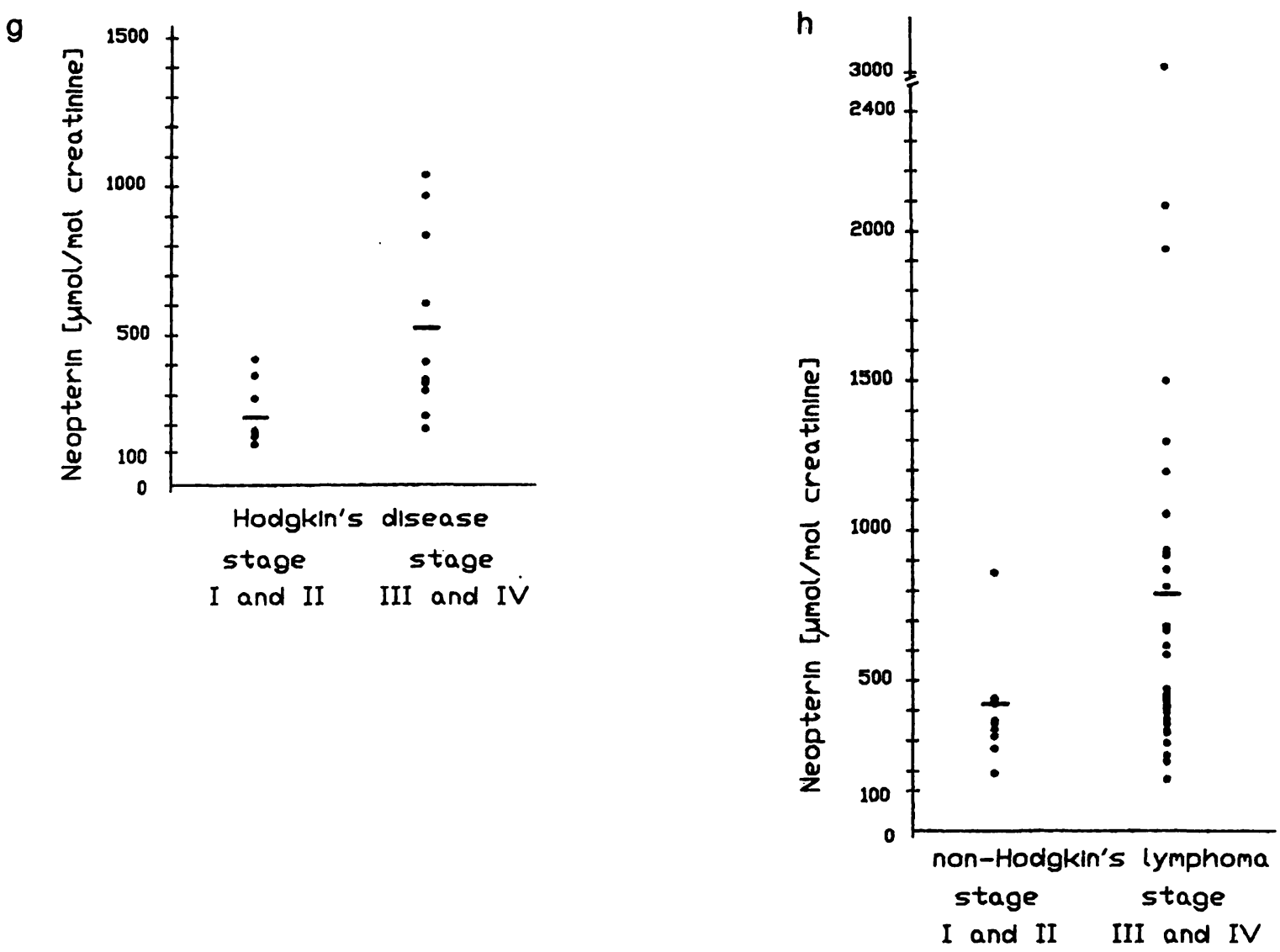

Fig. 1: Serum soluble interleukin-2 receptor and urinary neopterin concentrations in relation to clinical phase (a-d) and stage $(\mathrm{e}-\mathrm{h})$.
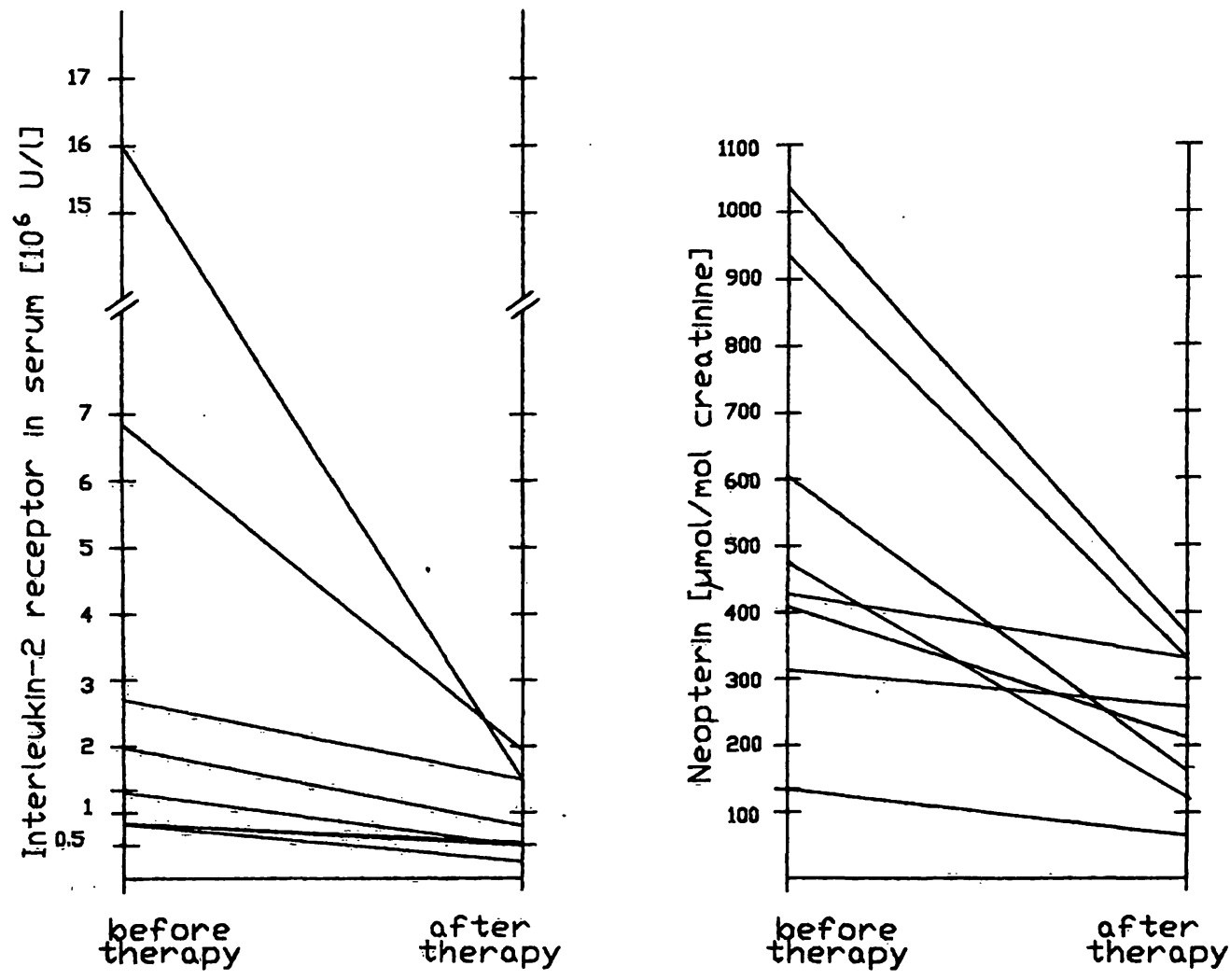

Fig. 2: Serum soluble interleukin-2 receptor and urinary neopterin in a longitudinal study of eight patients which achieved remission. 
tion of the values, while their resurgence generally indicates a relapse. Abnormally high blood soluble interleukin-2 receptor concentration is also an important index of negative prognosis in Hodgkin's disease $(22,34)$.

The biological mechanisms underlying our clinical findings are not yet fully understood. In lymphomas and leukaemias, the concentrations of soluble interleukin-2 receptors in the blood would appear to depend largely on direct neoplastic production, this assuming the characteristics of a classical tumour marker.

In certain cases (as demonstrated by studies on experimental lymphomas and as appears to occur in solid tumours), the increase in blood soluble interleukin-2 receptors, unrelated to the expression of interleukin-2 receptors on the membrane of the neoplastic cells, might indicate a modified macrophage-related activation of lymphocytes and/or monocytes which is of autonomic genesis or induced by the neoplasia ( 9 , 16, 17).

Increases in urine neopterin have been observed to be correlated strictly with the level of activity of the disease, be it Hodgkin's or non-Hodgkin's lymphoma (correlation being particularly significant in nonHodgkin's lymphoma), and are therefore useful in the clinical monitoring of patients $(25,28,37)$. Account must also be taken of the importance of urinary neopterin in prognosis: patients with lower urinary neopterin values survive longer than those with higher values, regardless of the clinical stage of the disease $(21,24)$.

In our experience, neopterin concentrations that are high during the clinical remission phase after induction therapy (or higher than those at the onset of the disease) are, compared with other classical quantities, the most significant in predicting early relapse $(25$, $28,29,30$ ). A recent multivariate survival analysis of the prognosis of multiple myeloma in fact showed that the predictive potential of neopterin in serum is greater than that of interleukin- 6 , a potent myeloma cell-growth factor that reflects disease severity in human plasma cell dyscrasias (38).

The biological mechanisms underlying the variations in the concentrations of urinary neopterin are as yet unclear. The increase in the concentrations of neopterin excreted in the urine appears first and foremost to be linked to activation of the immune response ( $T$ lymphocyte-macrophage system) induced in the host by specific tumour-cell antigens (19). However, neopterin may also be produced by specific tumour-cell subclones (14). In any event, activation of cell-mediated immunity often fails to lead to the effective killing of tumour cells, owing to an excess of antigen or to altered immune-cell function.

Very recent preliminary studies point to the possible importance, in cases of neoplasia, of assaying soluble interleukin-2 receptors and urinary neopterin at the same time, because high concentrations of soluble interleukin-2 receptors are reported in the same diseases that feature enhanced excretion of neopterin in the urine $(39,40)$.

To conclude, the results of our novel study of blood soluble interleukin -2 receptors and concomitant urinary neopterin confirms the importance of these two quantities as putative clinical markers in cases of lymphoma. The increases in concentrations reflect the development of the disease during the active stages, while decreasing concentrations correlate with the degree of response to therapy. The overall increase at the onset of the disease assumes a specific negative prognostic significance in the prediction of the interval of freedom from the disease and ultimate survival. However, a clearer picture emerges from urinary neopterin values; they correlate more closely with general symptomatology, with the clinical stage and with the routine analyses.

The observed differences between the two markers may be related to an ongoing immune response with peculiar activation of macrophages, which are the main source of neopterin. Macrophages are also able to modulate the inflammatory response by interaction with complement, release of hydrolases and proteases, the formation of peroxides, and the production of interleukin 1 and tumour necrosis factor which induce fever by their action on regulatory centres of the hypothalamus. From a clinical point of view, the above mentioned relationships appear to be further confirmed by the direct and significant correlation between urinary neopterin concentrations, clinical variables and general symptomatology.

The extent to which the specific activation of the Tlymphocyte-macrophage system, as revealed by the markers in question, depresses or enhances the immune response remains to be clarified.

Finally, the reported (41) increase in blood soluble interleukin-2 receptors and neopterin concentrations during immunotherapy of cancer with interleukin-2 emphasizes the need for a detailed study of the various cytokinetic effects on immune-cell modulation. Such studies are important for the design of targeting therapy appropriate to individual cases, with a view to boosting the body's anti-tumoral defences. 


\section{References}

1. Farrar, J. J., Benjamin, W. R., Hilfiker, M. L., Howard, M., Farrar, W. L. \& Fuller-Farrar, J. (1982) The biochemistry, biology, and role of interleukin-2 in the induction of cytotoxic $\mathrm{T}$ cell and antibody-forming $\mathrm{B}$ cell responses. Immunol. Rev. 63, 129-132.

2. Grimm, E., Mazumder, A., Shang, H. \& Rosemberg, S. (1982) Lymphokine-activated killer cell phenomenon. J. Exp. Med. 155, 1823-1825.

3. Herman, F., Cannistra, S. A., Levine, H. \& Griffin, J. D. (1985) Expression of interleukin 2 by gamma interferoninduced human leukemic and normal monocyte cells. $J$. Exp. Med. 162, 1111-1115.

4. Jacques Y., La Mauff, B., Boeffard, F., Godard, A. \& Soulillou, J. P. (1987) A soluble interleukin 2 receptor produced by a normal alloreactive humane $\mathrm{T}$ cell clone binds interleukin 2 with low affinity. J. Immunol. 139, $2308-2316$.

5. Rubin, L. A., Jay, G. \& Nelson, D. L. (1986) The released interleukin 2 receptor binds interleukin 2 efficiently. J. Immunol. 137, 3841 - 3844 .

6. Rubin, L. A., Kurmann, C. C., Fritz, M. E., Biddison, W. E., Boutin, B., Yarchoan, R. \& Nelson, D. L. (1985) Soluble interleukin-2 receptors are released from activated human lymphoid cells in vitro. J. Immunol. 135, 3172-3176.

7. Chilosi, M., Semenzato, G., Vinante, F., Menestrina, F., Piazzola, E., Focchiatti, V., Sabbioni, R., Zanotti, R. \& Pizzolo, G. (1989) Increased levels of soluble interleukin-2 receptor in non-Hodgkin's lymphomas. Am. J. Clin. Pathol. 92, 186- 191.

8. Pizzolo, G., Chilosi, M. \& Semenzato, G. (1987) The soluble interleukin-2 receptor in haematological disorders. Br. J. Haematol. 67, 377-380.

9. Lotze, M. T., Custer, M. C., Sharrow, S. O., Rubin, L. A., Nelson, D. L. \& Rosemberg, S. A. (1987) In vivo administration of purified human interleukin-2 to patients with cancer: development of interleukin-2 receptor positive cells and circulating soluble interleukin-2 receptors following interleukin-2 administration. Cancer Res. 47, 2188-2195.

10. Rovelli, F., Lissoni, P., Barni, S., Tancini, G., Conti, A. \& Maestroni, G. J. M. (1989) Sera from cancer patients with high levels of soluble interleukin-2 receptors can in vitro inhibit the interleukin-2 induced LAK generation. International Congress on Strategies in Cancer Medical Therapy, p. 99, Rimini-Riccione.

11. Colvin, R. B., Fuller, T. C., Mackeen, L., Kung, P. C., Ip, S. H. \& Cosimi, A. B. (1987) Plasma interleukin-2 receptor levels in renal allograft recipients. Clin. Immunol. Immunopathol. 43, 273-277.

12. Durno, A. G., Ho, D. R., Schocley, R. T., Hirsch, M. S., Mackeen, L. \& Ip, S. H. (1986) Serum interleukin-2 (IL$2 \mathrm{R}$ ) levels in human immunodeficiency virus (HIV) infection. Blood 68, 124-126.

13. Pizzolo, G., Vinante, F., Sinicco, A., Semenzato, G. \& Chilosi, M. (1987) Increased levels of soluble interleukin-2 receptor in the serum of patients with human immunodeficiency virus infection. Diag. Clin. Immunol. 5, 180-183.

14. Fuchs, D., Hausen, A. \& Reibnegger, G. (1988) Neopterin as a marker for activated cell-mediated immunity. Immunol. Today $9,150-154$.

15. Huber, C., Bachtelor, Jr., Fuchs, D., Hausen, A., Lang, A., Niederwieser, D., Reibnegger, G., Swetly, P., Troppmair, J. \& Wachter, H. (1984) Immune response-associated production of neopterin: Release from macrophages primarily under control of interferon. J. Exp. Med. 160, 310-316.

16. Huber, C., Fuchs, D., Hausen, A., Margreiter, R., Reibnegger, G., Spielberger, M. \& Wachter, H. (1983) Pteridines as a new marker to detect human $T$ cells activated by allogeneic or modified self major histocompatibility complex determinants. J. Immunol. 130, 1047-1050.
17. Nelson, D. L., Rubin, L. A., Kurman, C. C., Fritz, M. E. \& Boutin, B. (1986) An analysis of the cellular requirements for the production of soluble interleukin-2 receptors in vitro. J. Clin. Immunol. 6, 114-120.

18. Rokos, H., Rokos, K., Frisius, H. \& Kirstaedter, H. I. (1980) Altered urinary excretion of pteridines in neoplastic disease. Determination of biopterin, neopterin, xanthopterin and pterin. Clin. Chim. Acta 105, 275-280.

19. Aulitzky, W., Frick, J., Fuchs, D., Hausen, A., Reibnegger, G. \& Wachter, H. (1985) Significance of urinary neopterin in patients with malignant tumors of the genitourinary tract. Cancer 55, 1052-1055.

20. Piccinini, L., Federico, M., Zironi, S., Pini, L. A., Cirillo, M. \& Silingardi, V. (1987) Utilità clinical del dosaggio della neopterina urinaria in oncologia. X Convegno Regionale AIOM, Ferrara.

21. Santelli, G., Marfella, A., Abate, G., Comella, P., Nitsh, F. \& Perna, M. (1986) Urinary neopterin levels in hematologic malignancies. Tumori $72,139-143$.

22. Pui, C. H., Ip, S. H., Thompson, E., Wilimas, J., Brown, M., Dodge, R. K., de Hoyos, R. A., Berard, C. W. \& Crist, W. M. (1989) High serum interleukin-2 receptor levels correlate with a poor prognosis in children with Hodkin's disease. Leukemia 3, 481-484.

23. Wagner, D. K., Kiwanuka, J., Edwards, B. K., Rubin, L. A., Nelson, D. L. \& Magrath, I. T. (1987) Soluble interleukin-2 receptor levels in patients with undifferentiated and lymphoblastic lymphomas: Correlation with survival. J. Clin. Oncol. 5, 1262-1274.

24. Abate, G., Comella, P., Marfella, A., Santelli, G., Nitsch, F., Fiore, M. \& Perna, M. (1989) Prognostic relevance of urinary neopterin in non Hodgkin's lymphomas. Cancer $63,484-489$.

25. Denz, H., Grunewald, K., Thaler, J., Huber, H., Fuchs, D., Hausen, A., Reibnegger, G., Werner, E. R. \& Wachter, H (1989) Urinary neopterin as a prognostic marker in haematological neoplasias. Pteridines 1, 167-170.

26. Kawasaki, H., Watanabe, H., Yamada, S., Watanabe, K. \& Suyama, A. (1988) Prognostic significance of urinary neopterin in patients with hepatocellular carcinoma. Tohoku J. Exp. Med. 155, 311-318.

27. Lewenhaupt, A., Ekman, P., Eneroth, P., Eriksson, A., Nilsson, B. \& Nordstrom, L. (1986) Serum levels of neopterin as related to the prognosis of human prostatic carcinoma. Eur. Urol. 12, 422-425.

28. Piccinini, L., Zironi, S., Federico, M., Pini, L. A. \& Luppi, G. (1991) Urinary neopterin in malignant lymphoma. Int. J. Biol. Markers 6, 231-236.

29. Reibnegger, G., Bichler, A., Dapunt, O., Fuchs, D., Fuith, L. C., Hausen, A., Hetzel, H., Lutz, H., Werner, E. R. \& Wachter, H. (1986) Neopterin as a prognostic indicator in patients with carcinoma of the uterine cervix. Cancer Res. 46, 950-955.

30. Reignegger, G., Hetzel, H., Fuchs, D., Fuith, L. C., Hausen, A., Werner, E. R. \& Wachter, H. (1987) Clinical significance of neopterin for prognosis and follow-up in ovarian cancer. Cancer Res. 47, 4977-4981.

31. Carbone P. P., Kaplan, H. S., Musshoff, K., Smithers, D. W. \& Tubiana M. (1971) Report of the committee on Hodgkin's Disease Staging Classification. Cancer Res. 31, 1860-1861.

32. National Cancer Institute sponsored study of classification of non-Hodgkin's lymphomas (1982) Summary and description of a working formulation for clinical usage. Cancer 49, 2112-2135.

33. Greene, W. C., Leonard, W. J., Depper, J. M., Nelson, D. L. \& Waldmann, T. A. (1986) The human interleukin-2 receptor: Normal and abnormal expression in $\mathrm{T}$ cells and in leukemias induced by the human T-lymphotropic retroviruses. Ann. Intern. Med. 105, 560-572. 
34. Pizzolo, G., Chiloso, M., Vinante, F., Pazzo, F., Lestani, M., Perona, G., Benedetti, F., Tedeschini, G., Vincenzi, C., Trentin, L. \& Semenzato, G. (1987) Soluble interleukin-2 receptors in the serum of patients with Hodgkin's disease. Br. J. Cancer 55, 427-428.

35. Pui, C. H., Ip, S. H., Kung, P., Dodge, R. K., Berard, C. W., Crist, W. M. \& Murphy, S. B. (1987) High serum interleukin-2 receptor levels are related to advanced disease and a poor outcome in childhood non-hodgkin's lymphoma. Blood 70, 624-628.

36. Semenzato, G., Foa, R., Agostini, C., Zambello, R., Trentin, L., Vinante, F., Benedetti, F., Chiloso, M. \& Pizzolo, G. (1987) High serum levels of soluble interleukin-2 receptor (sIL-2R) in patients with B chronic lymphocytic leukemia. Blood 70, 396-400.

37. Hausen, A., Fuchs, D., Grunewald, K., Huber, H., Konig, K. \& Wachter, H. (1982) Urinary neopterin in the assessment of lymphoid and myeloid neoplasia, and neopterin levels in haemolytic anaemia and benign monoclonal gammopathy. Clin. Biochem. 15, 34-37.
38. Reibnegger, G., Krainer, M., Herold, M., Ludwig, H., Wachter, H. \& Huber, H. (1991) Predictive value of interleukin-6 and neopterin in patients with multiple myeloma. Cancer Res. 51, 6250-6253.

39. Kuzmits, R., Ludwig, H., Legenstein, E., Szekeresz, T., Kratzik, C. \& Hofbauer, J. (1986) Neopterin as tumor marker: Serum and urinary neopterin concentrations in malignant disease. J. Clin. Chem. Clin. Biochem. 24, 119125.

40. Mura, P., Piriou, A., Tallineau, C. \& Reiss, D. (1986) Urinary neopterin: Its value in the study of various neoplasms. Ann. Biol. Clin. 44, 505-510.

41. Lissoni, P., Tisi, E., Brivio, F., Barni, S., Rovelli, F., Perego, M. \& Tancini, G. (1991) Increase in soluble interleukin-2 receptor and neopterin serum levels during immunotherapy of cancer with interleukin-2. Eur. J. Cancer 27, 1014-1016.

Prof. Lino Piccinini Istituto Clinica Medica II Via del Pozzo, Policlinico I-41100 Modena Italy 